\title{
Development of a low cost force platform for biomechanical parameters analysis
}

\author{
Marcelo Guimarães Silva ${ }^{*}$, Pedro Vieira Sarmet Moreira ${ }^{2}$, Henrique Martins Rocha ${ }^{3}$ \\ ${ }^{1}$ Biomechanics Laboratory, Mechanical Engineering Department, Faculty of Engineering of Guaratinguetá, São Paulo State \\ University, Guaratinguetá, SP, Brazil. \\ ${ }^{2}$ Laboratory of Movement Analysis and Exercise Physiology, Biomedical Engineering Program, Federal University of Rio de \\ Janeiro, Rio de Janeiro, RJ, Brazil. \\ ${ }^{3}$ Department of Production Engineering, Faculty of Technology, Rio de Janeiro State University, Resende, RJ, Brazil.
}

\begin{abstract}
Introduction: The maintenance of balance and body orientation during standing is essential to perform different activities. One of the devices used to measure balance them is the force platform. This device measures the ground reaction force (GRF) and displacement of the center of pressure (COP), both biomechanical parameters involved in human motion. This article proposes a new design for non-commercial low-cost force platforms for scientific research purposes. Methods for calibration and validation are also described. Methods: A force platform, developed according to International Standards of Measurement and dedicated to measuring feet contact forces was built for approximately one tenth of the cost of commercial platforms. Calibration was performed by loading known masses, centralized or distributed, on the platform. An experimental study was conducted with four volunteers in different conditions to validate and verify the practical applicability of the device. Results: The platform calibration showed an adequate connectivity, linearity and reliable measurement of the variables proposed in this research, being suitable for studies of human postural behavior. Conclusion: Based on the validation results, we believe the low-cost platform can be used as stabilometric device to measure postural control and balance in clinical or sports experiments. However future studies will be required to provide a final validation and compare its performance with other force platforms.
\end{abstract}

Keywords Force platform, Biomechanical parameters, Low-cost development, Ground-reaction force, COP displacement.

\section{Introduction}

The maintenance of balance and body orientation during standing is essential to perform different activities, from daily life tasks to specific sport movements. One of the instruments used to analyze the kinetics of different human body joints is the force plate or force platform, a dynamometric instrument for biomechanical gait evaluation, balance assessments, and jump kinetic measurements (Barela and Duarte, 2011; Dias et al., 2011; Urquiza, 2005). Force plates (FP) monitor changes in movement conditions through the quantification of the dynamic variation in the ground reaction force (GRF) along the

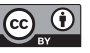

This is an Open Access article distributed under the terms of the Creative Commons Attribution License, which permits unrestricted use, distribution, and reproduction in any medium, provided the original work is properly cited.

How to cite this article: Silva MG, Moreira PVS, Rocha HM. Development of a low cost force platform for biomechanical parameters analysis.ResBiomedEng.2017;33(3):259-268.DOI:10.1590/2446-4740.01217

*Corresponding author: Mechanical Engineering Department, Faculty of Engineering of Guaratinguetá, São Paulo State University - UNESP, Av. Dr. Ariberto Pereira da Cunha, 333, CEP 12516-410, Guaratinguetá, SP, Brazil. E-mail: marceloguimas@bol.com.br

Received: 27 February 2017/ Accepted: 14 August 2017 contact phase, being used in biomechanics laboratories to study motion of human and animal subjects, during locomotion, running, jumping, or in daily life tasks.

A FP consists of a pair of rigid flat plates, one over another, with force sensors between them, which provide electrical signals relative to the applied forces. The sensors monitor the force applied in the medial-lateral $(\mathrm{X})$, anteroposterior $(\mathrm{Y})$, and vertical $(\mathrm{Z})$ directions, and the three force moment components related to the GRF, Mx, My, and Mz (Barela and Duarte, 2011; Duarte and Freitas, 2010).

The analysis of human movements and postural balance abilities is measured through three-dimensional components: two coordinates related to the individual's orientation on the top of the platform surface, i.e., anteroposterior direction (AP) and mediolateral direction (ML), and the GRF in the center of pressure (COP), defined as a point where the total sum of vertical force vectors acts on the support surface.

Parameters derived from COP trajectories measured by a laboratory grade force plate are considered the gold standard for balance performance (Huurnink et al., 2013), since balance training and testing have an 
important role in research on elderly fall prevention, rehabilitation of neurological and orthopedic patients, sport performance improvement, and reduction of injury risk (Gil-Gómez et al., 2011).

However, FPs are usually expensive, sometimes difficult to operate and their lack of portability limits their use outside laboratories. According to Duarte and Freitas (2010) and Barela and Duarte (2011), commercial FP prices are around US $\$ 10,000$ to US $\$ 20,000$. Table 1 shows data from the most popular commercial force platforms.

Due to the high cost of existing force platforms, the development of simpler low-cost models for biomechanical parameters analysis is desirable (Alvarenga et al., 2011), mainly due to the fact that there is a shortage of good resolution force platforms at affordable prices. Within the existing low-cost commercial platforms, the Wii Balance Board (WBB), advice initially designed as a video-game controller, is a relatively cheap ( $<$ US $\$ 100)$ and portable equipment, suggested by Huurnink et al. (2013) as a valid tool for quantifying COP trajectory, overall amplitude and velocity.

However, Pagnacco et al. (2011) compared WBB with a commercial force platform and identified severe limitations, such as the low sample rate, the unavailability of horizontal forces, a larger amount of noise, besides an inconsistent sampling interval, and occasional glitches in the data as manufacturer advised the maximum load of $1962 \mathrm{~N}$. Authors inferred that WBB is not a valid measuring tool of standing balance, therefore not suitable for measuring fast or strength activities movements widely evaluated by the force platform.

Most of the FPs used in Brazil are imported. Besides the high prices, which are increased by freight and import taxes, technical assistance issues and spare parts' availability are source of many difficulties for labs and researchers.

In order to close this gap, we propose a new non-commercial low-cost FP for biomechanical purposes, to be used to analyze GRF and COP. The novelty of this work is associated with the acquisition of local know-how in order to develop a device characterized by low cost, construction simplicity, easiness of maintenance and local availability of spare parts, yet providing effectiveness and reproducibility of data. Another important contribution is the low total weight, which facilitates transport and handling.

\section{Methods}

There are different plate configurations based on sensors positioning: a) a single sensor in the center; b) triangular platform, with sensors in its three corners; and c) the most common configuration, rectangular platform, with sensors at the corners.

The proposed platform was designed, fabricated and calibrated in the Mechanical Laboratory of the São Paulo State University - UNESP (Guaratinguetá, Brazil), with four load cells arranged in a rectangular shape.

\section{Force platform design}

There are various types of sensors used in FP: Piezoelectric sensors are known for their excellent linearity and reactivity but cannot be easily adapted to surfaces due to their large size (Duarte and Freitas, 2010; Herran et al., 2014); Capacitive sensors are based on the principle of condenser capacity changes, according to different parameters. They are widely used mainly in wearable gait analysis systems (Herran et al., 2014); Piezoresistive sensors are the most widely used in off-the-shelf platforms, mainly for gait analysis, measuring forces and moments, being sensitive to accelerations as well; Strain gauges are bonded to the surface of a mechanical structure and present relevant advantages over piezoelectric and piezoresistive sensors, such as better stability for long-term measurements, providing absolute measurements instead of relative ones (Roriz et al., 2014).

The proposed force platform was developed according to International Standards of Measurement, with four strain gauge transducers (model J2A-06-SO38-350, developed by Micro Measurements), gain factor 2, total load capacity of $3600 \mathrm{~N}$, with four SAE 630 stainless steel body binocular bending beam load cells (Flexar-ITX), $900 \mathrm{~N}$ capacity each, and sensitivity of $2 \mathrm{mV} / \mathrm{V}$ (recommended configuration for the reading of vertical forces applied to the loading point).

Due to its load cell arrangement, the FP was designed and constructed in order to measure the vertical and horizontal components of the force and the coordinates of the COP. Thus, for this force platform, which has

Table 1. Commercially main force platforms available.

\begin{tabular}{ccccc}
\hline Manufacturer & Type & Dimensions (mm) & Internal amplifiers \\
\hline AMTI & Load Cells & $464 \times 508$ to $610 \times 1220$ & Non & \\
Bertec & Load Cells & $464 \times 508$ to $900 \times 900$ & Yes \\
Kistler & Piezoelectric crystal & $500 \times 500$ to $600 \times 900$ & Yes $(1$ model) \\
EMG System & Load Cells & $500 \times 500$ & Non & Non \\
Cefise & Load Cells & $600 \times 600$ & \\
\hline
\end{tabular}


four uniaxial load cells, arranged in a rectangular shape, $\mathrm{Fz}$ is equal to the sum of the vertical reaction forces of each load cell. Considering that $\Sigma$ Moments $=0$ and $\Sigma$ Forces $=0$, the COP must be located exactly at the center of the system. The COP location was calculated by the following equations:

$$
\begin{aligned}
& \text { COPap }=x / 2[(F 1+F 4)-(F 2+F 3) / F z] \\
& \text { COPml }=y / 2[(F 3+F 4)-(F 1+F 2) / F z]
\end{aligned}
$$

where $\mathrm{x}$ and $\mathrm{y}$ correspond to the width and length of the usable area in the force platform, respectively, $\mathrm{F}$ is the vertical reaction force of each load cell, Fz is the sum of F1, F2, F3 and F4. According to Dias et al. (2011) those equations are appropriated to systems with four uniaxial load cells arranged in a rectangular shape. The usable area of the FP corresponds to the rectangular area that has the centers of the four load cells as corners.

An important aspect related to construction of a force platform is the natural frequency, which must be much higher than the frequencies of the signals to be measured. Therefore, the platform, made out of a $500 \mathrm{~mm}$-side length square piece of $10 \mathrm{~mm}$-thick $5052 \mathrm{~F}$ aluminum plate, weighting $6.30 \mathrm{~kg}$, was positioned on a solid structural foundation. The material properties of the plate are presented as follows:

- Young's Modulus of Elasticity (E) $7.31 \times 10^{10} \mathrm{~N} / \mathrm{m}^{2}$;

- Poisson's coefficient (v) 0.3333;

- Density (p) $2.70 \times 10^{3} \mathrm{~kg} / \mathrm{m}^{3}$;

- Yield Strength $\left(\mathrm{R}_{\mathrm{e}}\right) 8.07 \times 10^{7} \mathrm{~N} / \mathrm{m}^{2}$.

A platform with maximum rigidity and minimum mass results in: (a) small deformations, (b) uncoupling (applying load in the $\mathrm{x}$-axis should not appear component in y-and z-axes), (c) good linearity, and (d) low hysteresis. The rigidity of the platform and the fixation of the platform surfaces in the load cells are also important aspects to obtain higher frequencies (Bagesteiro et al, 1998).

A full Wheatstone bridge configuration was used in each load cell. The four load cells were placed in each corner of the plates, equidistant $0.03 \mathrm{~m}$ from the edges, as shown in (Figure 1a) and supported by four feet articulated by spherical steel. Figure $1 \mathrm{~b}$ shows the mechanical drawing of this specific load cell. A test gauge (yellow piece) with the exact format of iron weights used as mass during the calibration static procedure was fixed in the center of the platform base (Figure 1c).

The overall cost to fabricate this platform was around US $\$ 1,000$ - around one tenth of the cost of commercially available force platforms.

\section{Calibration procedure}

Along the experiment, sensor readings were made in volt (V) units. Therefore, a calibration procedure was required to convert the signals from the load cells (V) to force unit (N). To do so properly, it was necessary to determine the static and dynamic characteristics of the sensor (i.e. linearity, hysteresis), a mandatory step on applications that require continuous force measurement accuracy (Urquiza, 2005). Hence, the calibration was performed to determine the relationship between the forces applied to the platform and the output voltages from the strain gauge measurement system, and to verify the linearity, hysteresis and standard error of the instrument for each axis.

Previous researches (Alvarenga et al., 2011; Urquiza, 2005) presented methods and demonstrated various calibration procedures and showed the importance of this being done properly in order to achieve reproducible results. To calibrate the proposed FP, we chose the method proposed by Urquiza (2005).

The static calibration of the load cells was performed using known loads. The loads were placed on top of the load cells for 10 seconds per trial, in a total of four

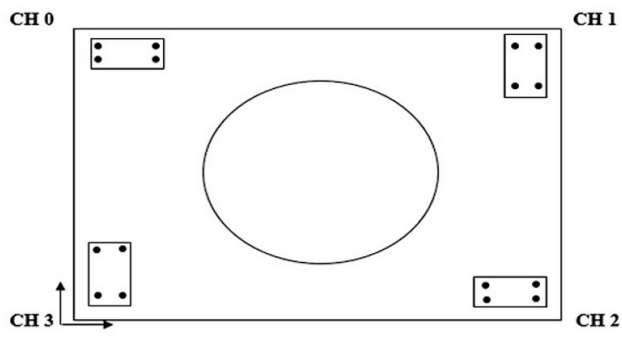

(a)

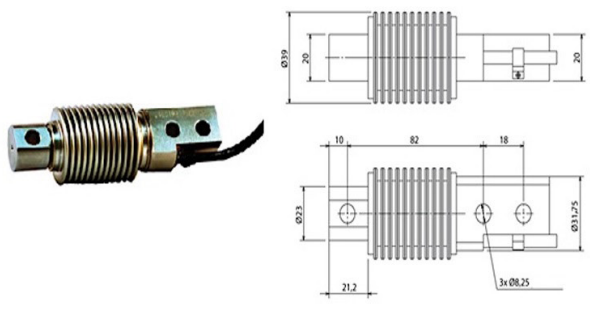

(b)

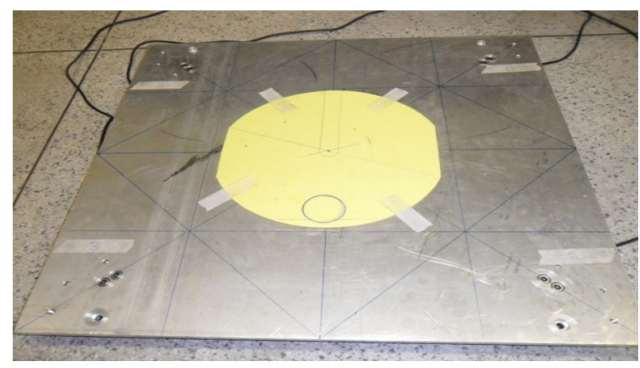

(c)

Figure 1. Proposed low-cost force platform with the four load cells (a) and their respective dimensions (mm) and geometry (b); (c) tested gauge fixed on the top of the force platform. 
separate trials for each load cell. The average value was then calculated and adopted as reference.

To calculate moments, we applied the method proposed by Gurgel et al. (2005). This method consists of positioning weights in central area of the force platform and allowed us to generate a calibration matrix. The force elements (Mx, My and Fz) were calculated according to Equation 3 (Gurgel et al., 2005).

$$
\begin{aligned}
& V M x=A+B-C-D \\
& V M y=A-B-C+D \\
& V F z=A+B+C+D
\end{aligned}
$$

where $\mathrm{A}=\mathrm{F} 1, \mathrm{~B}=\mathrm{F} 2, \mathrm{C}=\mathrm{F} 3, \mathrm{D}=\mathrm{F} 4$; Fz is the sum of F1, F2, F3 and F4.

Therefore, for this static calibration procedure, we used standard weights placed at the center of the platform (Figure 2a). A linear regression was used for the values of loading and unloading of each force and moment elements for each axis were calculated using Microsoft Office Excel 2010. This procedure allowed us to calculate the angular coefficient (Gurgel et al., 2005), which is necessary for the construction of the calibration matrix, as well as the sensitivity matrix.

By means of the vertical and horizontal calibration, it was also possible to obtain the linear adjustment, defined as the quotient between the upper point of the calibration curve and the full scale of each transducer in the deformation curve, equivalent to $900 \mathrm{~N}$.

To perform the horizontal calibration, we have developed a specific calibration procedure (Figure 2b), which used of a rigid structure fixed to the ground by four screws. A steel cable was secured on one side to the platform edge, connected to a steel structure fixed to the ground facing the platform, and pulling only in the horizontal direction.

In addition, the hysteresis of the transducers was obtained by means of a load overlapping procedure. For both directions measured by this platform, we applied previously known loads, starting from zero until $900 \mathrm{~N}$, without disconnecting the loading system at any time.

Furthermore, we calculated the sensitivity and hysteresis of the $\mathrm{Z}$-axis and the moments Mx and My. The calibration matrix of calibration was calculated based on Equation 4, as proposed by Gurgel et al. (2005). In addition, the calculation of this matrix was based on the slopes of the linear regression curves.

$$
\left\{\begin{array}{l}
V F_{z} \\
V M_{x} \\
V M_{y}
\end{array}\right\}=\left[\begin{array}{lll}
C_{11} & C_{12} & C_{13} \\
C_{21} & C_{22} & C_{23} \\
C_{31} & C_{32} & C_{33}
\end{array}\right] \times\left\{\begin{array}{c}
F_{z} \\
M_{x} \\
M_{y}
\end{array}\right\}
$$

To measure the accuracy and precision of the COP readings, we used the test of distributed load, which provides closest readings to reality in the stabilometric

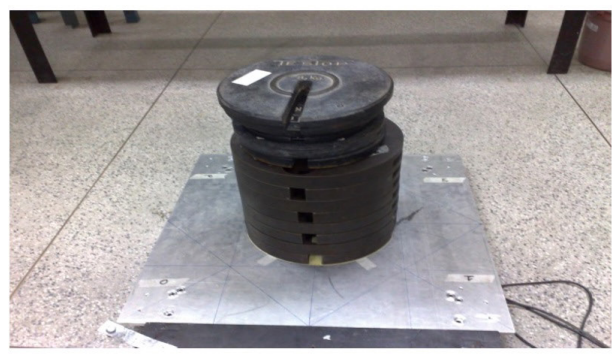

(a)

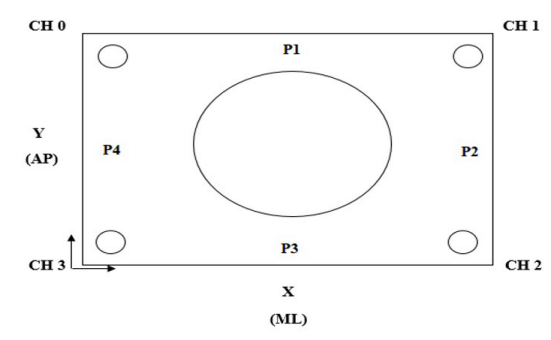

(b)

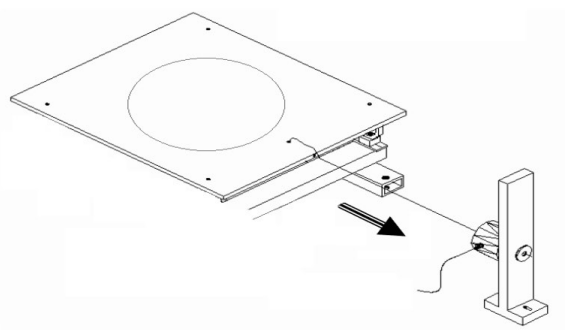

(c)

Figure 2. (a) Static calibration with load placed on the center of platform; (b) Schematic view of the horizontal platform calibration design; (c) The calibration procedure with 4 distinct points (P1, P2, P3, P4) located $100 \mathrm{~mm}$ away from the center of the platform (circunference).

platform as possible. This test was also used to simulate the load applied by the human feet in stabilometric evaluations, as proposed by Dias et al (2011). In this way, the load was applied in four different points (P1, P2, P3 and P4) located between the platform channels $0,1,2$ and 3 and $100 \mathrm{~mm}$ away from the center of the platform (Figure 2c). In this way, it was possible to measure the output of each load cell and compare them to the weight placed each point.

The signal captured by the four load cells was collected using a HBM Spider-8 conditioner, with CATMAN software, at an acquisition frequency of $200 \mathrm{~Hz}$.

After the installation of the four load cells on the platform and their respective calibration, a dynamic analysis was made to identify the natural frequencies of vibration of the platform, in accordance with previous study (Bagesteiro et al., 1998). The dynamic experimental readings were obtained through a method of impact, 
with an acceleration sensor (Silicon Designs, INC., Model: 2210-025); capacitive; scale: $\pm 25 \mathrm{~g}$; frequency: 0-1000 Hz; sensitivity: differential mode: $160 \mathrm{mV} / \mathrm{g}$; single-ended mode: $80 \mathrm{mV} / \mathrm{g}$; nominal output voltage: $2.5 \mathrm{~V}$ ) fixed on the top of the platform. An impact load was applied directly on the center of the platform using a rubber mallet. The FFT (Fast Fourier Transform) was calculated for the normal reaction force measured in order to obtain the resonance frequency of the material and, consequently, the frequency response of the platform for the applied impulse.

\section{Data collection}

The following procedure was executed for data acquisition, before starting the practical validation of the platform:

- Connect the platform and wait for stabilization of the load cell signals for about $15 \mathrm{~min}$ - until equilibrium between the strain-gages, to garantee minimum variation along the experiments;

- Standardization of force measures - data was collected with the subject in bipodal standing on the platform (measuring body weight) during $4 \mathrm{~s}$ in static position. Data was acquired with a HBM Spider8 conditioner (A/D converter: 16 bits resolution and 16 channels), with CATMAN software, at $200 \mathrm{~Hz}$ sampling frequency;

- Experimental data acquisition: Data collected using the HBM Spider8 conditioner, with CATMAN software at a sampling frequency of $100 \mathrm{~Hz}$. Signals were then filtered using a zero lag second-order low pass Butterworth filter, with a cutoff frequency of $10 \mathrm{~Hz}$;

- Upon completion of the data acquisition, a file contained all measures was saved and exported to Matlab (Math Works Inc., USA), to analyze GRF and COP displacements.

\section{Experimental procedure}

An experimental study consisting of static and dynamic tasks was performed with the purpose of validating the platform construction and evaluate its appropriateness in real use with humans. The sample consisted of 4 volunteers, aged between 16 and 18 years old (mean \pm standard deviation: $17.5 \pm 1.29$ years old), body weight of $65.0 \pm 4.02 \mathrm{~kg}$, and height $178.75 \pm 5.85 \mathrm{~cm}$. None of the volunteers reported any neurological or vestibular disorder or orthopedic condition, including lower limb injury in the six months prior to data collection. All volunteers had normal or corrected-to-normal vision. The study purpose and its procedures were explained to each subject, who signed an informed consent form prior to their participation.
With the force platform used as stabilometer, the GRF and Moment of Force were measured and then, variations of COP were recorded and analyzed with a customized Matlab routine (Math Works Inc., USA).

The outputs (GRFs, Moments and COPs) of the platform were configured according to the Cartesian coordinate system, where the axis $\mathrm{X}, \mathrm{Y}$ and $\mathrm{Z}$ represent the medio-lateral, the antero-posterior and the vertical axes. The origin of this system was located at the geometric center of the platform surface. In this way, two experiments were excuted to verify the COP practical functionality:

- Experiment 1: static or quiet standing, focused on clinic analysis. The experiment was performed with the volunteers in two different conditions: eyes open (EO) and eyes closed (EC), with three trials in each condition performed by each volunteer in random order. Volunteers were asked to sway as little as possible, while standing barefoot on the force platform in a natural position or normal standing (bipodal stance, feet abducted at $30^{\circ}$, heels separated by $3 \mathrm{~cm}$ ) during $30 \mathrm{~s}$, with arms hanging loosely by their sides. In EO condition, subjects were instructed to fix the eyes on a black cross marked in a vertical surface at eye level, $2.5 \mathrm{~m}$ away in front of them, while in EC condition, volunteers were oriented to keep the neck directly aligned over the spine and the head as most stable as possible;

- Experiment 2: dynamic analysis, purposed to investigate GRF and COP behavior during sportive gestures. For this experiment, the volunteers remained in unipodal stance, only with their left foot on the force platform. The volunteers performed a kick on a ball with the instep of the right foot, as accurately as possible, towards a target $(0.40 \mathrm{~m} \times 0.40 \mathrm{~m})$ with a $0.10 \mathrm{~m} \times 0.10 \mathrm{~m}$ bulls eye positioned $3.70 \mathrm{~m}$ away from them, at the ground level. During the kick, they remained on unipodal stance, most stable as it possible, with your left foot centralized on the platform. The kicking movement was arbitrarily divided into two successive phases: The backswing phase, reflecting kicking preparation, started with the raising of the right ankle until the maximal backward position of the limb, whereas the shooting phase, reflecting kicking targeting, started from the maximal backward position until foot contact with the ball toward the target. The beginning of the movement was considered T0, established as the first visible deflection of the right ankle kinematics signal, viewed off-line on a monitor screen. Thus, GRF and COP displacements were processed only from T0. Each volunteer performed 12 kicks, which 
were posteriorly analyzed. A time rest of $1 \mathrm{~min}$ between each kick was allowed.

\section{Data analysis}

The dependent variables analyzed in this study were used to describe the volunteers' postural behavior, including calculation of mean AP and ML amplitude (mm) and speed $(\mathrm{mm} / \mathrm{s})$ of COP displacement. In addition, the $\mathrm{COP}$ area $\left(\mathrm{mm}^{2}\right)$ and GRF (peak-norm) were calculated.

The amplitude of COP displacements indicated the mean deviation of $\mathrm{COP}$ in the $\mathrm{AP}$ and $\mathrm{ML}$ directions. It is a global measure allowing to estimate overall postural performance (Vuillerme et al., 2001). The mean speed of COP displacements was the sum of the displacement scalars divided by the sampling time. It represents the amount of activity required to maintain stability and provides a more functional measure of postural control (Geurts et al., 1993).

To obtain a measure of the COP spatial variability, we used a $95 \%$ sway confidence ellipse area of the COP, which was calculated from the dispersion measurements

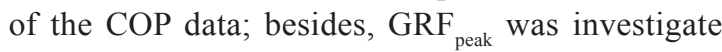
separately to each phase (backswing, shooting), and normalized by the timing.

\section{Results}

\section{Calibration}

Each individual load cell was evaluated with a load applied at the center of the platform. The sum of the outputs from the four load cells presented a correlation coefficient $\mathrm{R}^{2}=1$, in the load range of 0 to $900 \mathrm{~N}$, equivalent to the total capacity that each load cell can support.

As shown in the Figure 3, the load cells presented a linearity and hysteresis ideal for the test with error below $0.25 \%$ of the vertical and $0.31 \%$ of the horizontal for a full scale $(900 \mathrm{~N})$.

Concerning the components of FP (force and moments), the hysteresis and linearity were neasured. Hysteresis was calculated and presented the following results: $\mathrm{Mx}=4.91 \%, \mathrm{My}=7.16 \%, \mathrm{Mz}=6.04 \%$; and the linearity $\mathrm{My}=0.9872, \mathrm{Z}=0.9973, \mathrm{Mx}=0.9692$. The FP after the calibration process achieved all proposed objectives, showing a resolution of $0.003685 \mathrm{Nm}$ in $\mathrm{Mx}, 0.004327 \mathrm{Nm}$ in $\mathrm{My}$, and $0.035403 \mathrm{~N}$ in $\mathrm{Z}$ axis.

In addition, to measure the accuracy and precision of COP measurements, the test of distributed load was applied. Table 2 shows the values of $\mathrm{COP}_{\text {predicted }}$ and $\mathrm{COP}_{\text {measured }}$, demonstrating the accuracy of the proposed FP. The error was calculated by subtracting the $\mathrm{CoP}_{\text {measured }}$ from the $\mathrm{CoP}_{\text {predicted. }}$.
The response to the thrust applied on the platform in the dynamic experimental analysis presented different peaks of frequency in the vibration mode analysis. Table 3 shows the different frequencies, which progressively increased between the first and the fifth vibration mode analyzed.

The first peak of frequency occurred at approximately $110 \mathrm{~Hz}$, and the others occurred at higher frequencies, in which the highest was $267 \mathrm{~Hz}$. Thus, it was determined that the natural vibration frequency of this platform was not less than $110 \mathrm{~Hz}$.

\section{Experimental study}

In the first experiment, the analysis of the mean and standard deviation (SD) seen in Table 4 showed that, in normal bipodal stance, the maintenance of the equilibrium was more difficult in AP direction, with volunteers being capable of maintaining a more acceptable equilibrium in the ML direction, suggesting that more oscillations occurred in the anterior direction. These results were more exacerbated mainly when their vision was blocked (COP AMP mean: Eyes Open $=20.07 \mathrm{~mm}$ and $17.72 \mathrm{~mm}$ vs. Eyes Closed $=25.71 \mathrm{~mm}$ and $23.22 \mathrm{~mm}$, in AP and ML directions, respectively), i.e., vision helps minimizing postural sway and plays an important role in the maintenance of upright standing.

In the second experiment, the analysis of the mean and SD, showed that volunteers overall oscillated more during the backswing phase, which is related to preparation of the movement and beginning of the ballistic movement. Table 5 shows the results of the variables analyzed in each phase of kick. As seen, maintenance of the equilibrium was more difficulty in AP than ML direction (COP AMP mean: $\mathrm{AP}=21.77 \mathrm{~mm}, \mathrm{ML}=11.45 \mathrm{~mm}$ ), suggesting that more oscillations were found in anterior direction, mainly during the shooting phase, and that the equilibrium during the ballistic movement was more difficult on unipodal standing due the need to minimize postural sway. On the other hand, we observed that in the shooting phase, the volunteers showed better stability than in the backswing phase.

\section{Discussion}

The main aim of this study was to demonstrate and validate the construction and calibration of a non-commercial low-cost force platform, designed for scientific research purposes, in this specific case, the analysis of the human postural behavior.

The calibration results showed that the platform presented an adequate connectivity and was efficient for the measurement of the variables proposed in this study (GRF and COP variables). The hysteresis showed expected results for a low-cost FP (Gurgel et al., 2005); 
Load Cell n.1

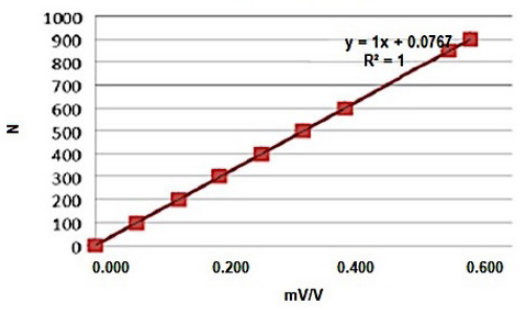

Load Cell n.3

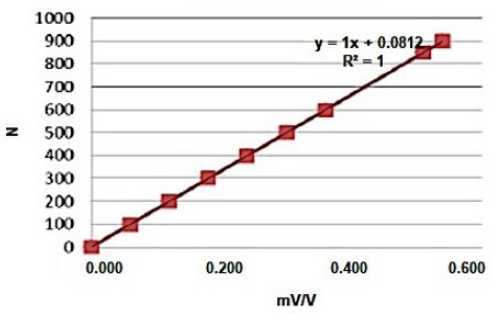

Load Cell n.1

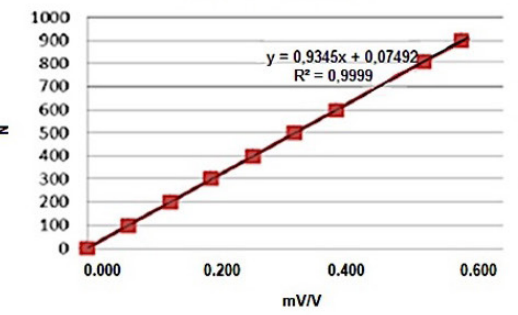

Load Cell n.3

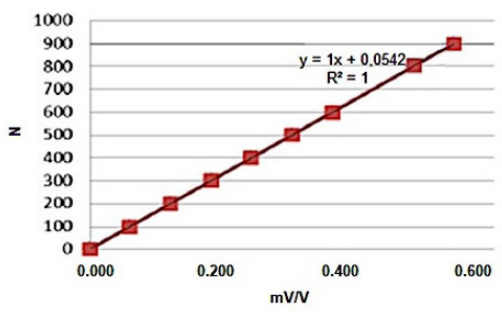

Load Cell n.2
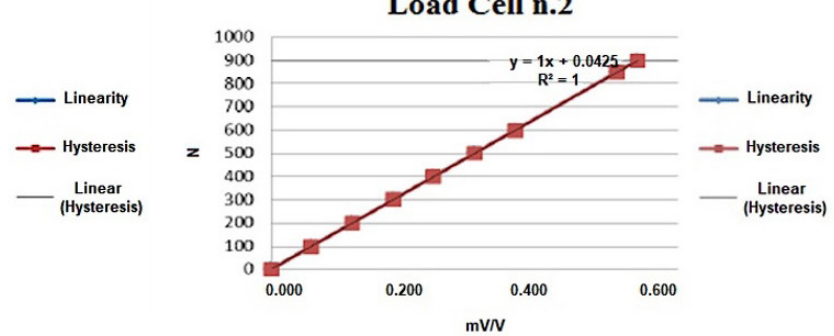

Load Cell n.4

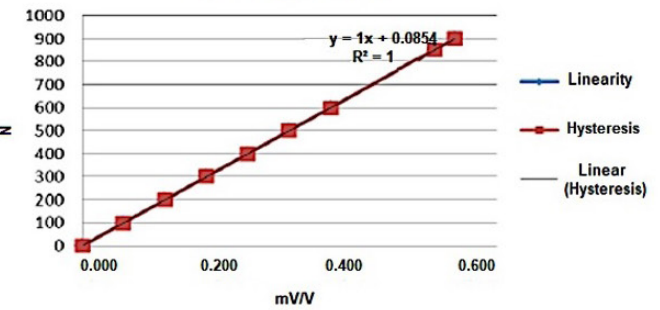

(a)

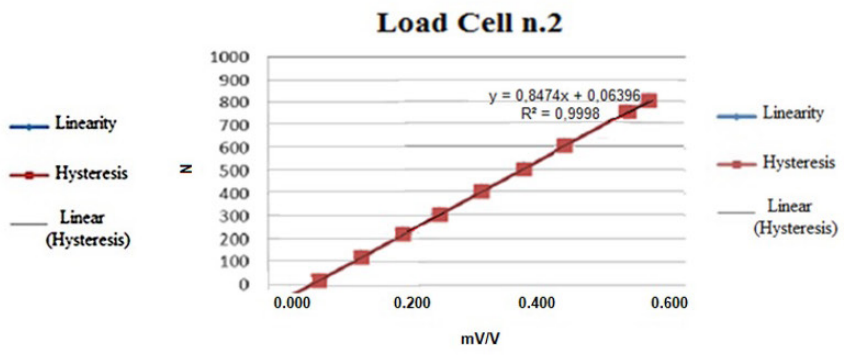

Load Cell n.4

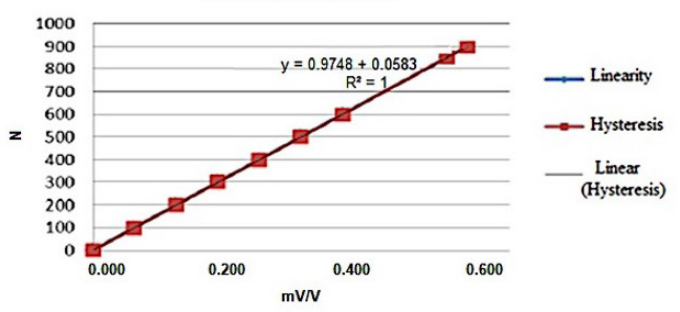

(b)

Figure 3. (a) Vertical and (b) Horizontal calibration results of the force platform ( 0 to $900 \mathrm{~N})$ for each load cell separately.

Table 2. Mean and standard deviation of the actual values of $\mathrm{COP}_{\text {predicted }}$ and $\mathrm{COP}_{\text {measured }}$ in both directions (AP, ML) obtained through the distributed load test.

\begin{tabular}{|c|c|c|c|c|}
\hline \multirow{2}{*}{$\begin{array}{c}\text { Point of } \\
\text { Loading application }\end{array}$} & \multicolumn{2}{|c|}{$\mathrm{COP}_{\mathrm{AP}}(\mathrm{mm})$} & \multicolumn{2}{|c|}{$\mathrm{COP}_{\mathrm{ML}}(\mathrm{mm})$} \\
\hline & Predicted & Measured & Predicted & Measured \\
\hline P1 & $18.76 \pm 0.36$ & $18.98 \pm 0.31$ & $10.02 \pm 0.50$ & $10.44 \pm 0.67$ \\
\hline $\mathbf{P 2}$ & $19.76 \pm 0.33$ & $20.03 \pm 0.75$ & $9.67 \pm 0.59$ & $10.01 \pm 0.47$ \\
\hline P3 & $19.82 \pm 0.23$ & $20.16 \pm 0.50$ & $9.80 \pm 0.61$ & $10.09 \pm 0.31$ \\
\hline P4 & $19.65 \pm 0.58$ & $19.90 \pm 0.40$ & $9.88 \pm 0.56$ & $10.27 \pm 0.87$ \\
\hline
\end{tabular}


in addition, the linearity was adequate when compared with that obtained by other authors (Gurgel et al., 2006). Overall, the force platform showed satisfactory resolution and sensitivity of curves, combined with a structural rigidity and low weight, with notorious cost advantage, related of most commercial platforms currently available in the market.

Along the calibration procedure we found errors of less than $1 \mathrm{~mm}$ in the COP location, in accordance with previous studies (Cedraro et al., 2008). In addition, we noticed that the COP measurement error found in the distributed load test, when the loads were closer to the edges of the platform, was higher than that observed in the application of the centralized load, contrary to previous studies (Dias et al., 2011; Rana, 2009). These differences can be explained probably due to an uneven load distribution on the plate, not well transferred to the four load cells or imperfections on the plate. Though this characteristic appears to be negative, it shows that a system designed in this manner can reduce the hysteresis effects (Dias et al., 2011).

The initial experiment, designed to evaluate the volunteers' ability to adapt their postural control in a vision and no-vision conditions, showed a decrease in postural stability in EC conditions, suggesting that the contribution of proprioceptive inputs (vision) is very important to the regulation of the posture, in accordance with (Kavounoudias et al., 1999). When vision was

Table 3. Frequencies obtained in different modes of vibration during the dynamic experimental acquisition of the platform.

\begin{tabular}{cc}
\hline Vibration mode & Frequency $(\mathbf{H z})$ \\
\hline 1 & 110 \\
2 & 176 \\
3 & 203 \\
4 & 259 \\
5 & 267 \\
\hline
\end{tabular}

blocked, the volunteers exhibited an increase in COP displacements, mainly in AP direction. On the other hand, the results showed also that they were able to provide a reorganization of postural control to take into account such condition, remained more stable in the ML direction. We suggested that this study could be applied to larger and distinct samples, such as older adults, to study the effects of paired functional balance associated with Parkinson's diseases, among others.

In addition, we investigated the practical applicability of this platform in a dynamic test. The purpose of this second experiment was to investigate the postural behavior in a soccer kicking task, characterized by high frequency body oscillation, due to a reduced supporting base and short task time $(<2.0 \mathrm{~s})$, demanding a high level of coordinated movement and balance to perform this task precisely.

Previous studies with young volunteers (Moreira et al., 2004; Rosa, 2010) found a GRF maximum value, produced by the supporting leg, of 1 to 1.2 body weight during the initial phases, and 2.2 to 3.2 body weight during kicking. These results showed a GRF peak variation mainly during the backswing phase in order to maintain balance and body adjustment during the preparation of the movement. In our experiments, we observed similar GRF peak variations when the volunteers performed a ballistic movement in the shooting phase.

COP analysis was carried out in both directions, due its importance to measure the sway movements imposed in precision kicking, where the postural balance depends mainly of the lateral and frontal oscillations of the supporting foot. Results of the mean amplitude and speed showed that volunteers swayed more in backswing phase, being more evident during the preparation of the movement, especially in the AP direction, in accordance with (Remaud et al., 2012). According to results showed in Table 5, an anterior body inclination occurred on the AP axis (backswing movement), probably due the

Table 4. Experimental results of the first experiment, represented by the mean and standard deviation (SD) of the $95 \%$ ellipse area ( $\left.\mathrm{mm}^{2}\right)$ for the two conditions: eyes open (EO) and eyes closed (EC). Mean COP amplitude (mm), and SD for the EO and EC conditions, in the AP and ML directions Mean COP speed ( $\mathrm{mm} / \mathrm{s})$, and SD for the EO and EC conditions, in the AP and ML conditions.

\begin{tabular}{|c|c|c|c|c|c|c|c|c|c|c|}
\hline \multirow[b]{2}{*}{$\frac{\grave{d}}{\stackrel{d}{E}}$} & \multicolumn{5}{|c|}{ Eyes Open } & \multicolumn{5}{|c|}{ Eyes Closed } \\
\hline & 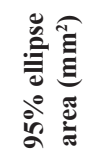 & 气 & 气 & $\hat{0}^{\circ} \stackrel{\circ}{\text { ह }}$ & 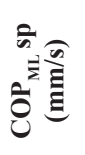 & 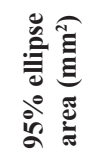 & $\hat{\circlearrowright}^{\stackrel{\Xi}{\Xi}}$ & 气 & $\hat{0}^{\stackrel{\circ}{n}} \stackrel{\hat{n}}{\Xi}$ & 仓ै \\
\hline $\mathbf{A}$ & 110.5 & 18.4 & 13.3 & 18.3 & 15.4 & 180.5 & 19.5 & 21.5 & 23.5 & 16.7 \\
\hline B & 127.0 & 22.3 & 19.6 & 31.0 & 22.5 & 190.4 & 31.7 & 23.8 & 34.2 & 23.8 \\
\hline $\mathrm{C}$ & 175.6 & 25.6 & 15.8 & 26.7 & 18.0 & 226.0 & 27.4 & 13.0 & 29.8 & 22.0 \\
\hline D & 156.8 & 14.0 & 22.2 & 27.8 & 20.1 & 240.2 & 27.4 & 23.22 & 28.57 & 21.75 \\
\hline Mean & 142.47 & 20.07 & 17.72 & 25.95 & 19.0 & 209.27 & 25.71 & 23.22 & 28.57 & 21.75 \\
\hline SD & 29.23 & 5.00 & 3.95 & 5.41 & 3.02 & 28.40 & 5.12 & 8.89 & 4.54 & 3.52 \\
\hline
\end{tabular}


Table 5. Experimental results of the second experiment, represented by the mean and standard deviation (SD) of the GRF (peak, norm) for the backswing and shooting phases, in the AP and ML directions. Mean COP amplitude (mm), and SD for the backswing and shooting phases, in the $\mathrm{AP}$ and ML directions. Mean COP speed ( $\mathrm{mm} / \mathrm{s})$, and SD for the backswing and shooting phases, in the AP and ML directions.

\begin{tabular}{|c|c|c|c|c|c|c|c|c|c|c|}
\hline \multicolumn{7}{|c|}{ Backswing } & \multicolumn{4}{|c|}{ Shooting } \\
\hline 离 & 总 & 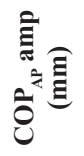 & 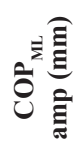 & के & 气ิ & 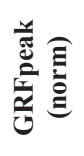 & 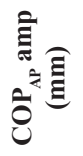 & 仓ٍ & 光 & के \\
\hline A & 1.83 & 15.8 & 9.7 & 51.3 & 20.0 & 2.31 & 18.9 & 7.6 & 40.8 & 18.7 \\
\hline B & 2.02 & 18.0 & 12.4 & 43.9 & 31.8 & 1.89 & 23.0 & 11.8 & 36.2 & 27.4 \\
\hline $\mathrm{C}$ & 1.44 & 21.4 & 14.2 & 54.8 & 16.4 & 2.12 & 20.3 & 17.4 & 44.3 & 19.9 \\
\hline D & 1.88 & 16.5 & 8.8 & 33.2 & 18.3 & 1.93 & 24.9 & 9.0 & 27.0 & 23.7 \\
\hline Mean & 1.79 & 17.92 & 11.27 & 45.8 & 21.62 & 2.06 & 21.77 & 11.45 & 37.07 & 22.42 \\
\hline SD & 0.24 & 2.49 & 2.47 & 9.55 & 6.94 & 0.19 & 2.68 & 4.33 & 7.49 & 3.94 \\
\hline
\end{tabular}

necessity to perform a more controlled movement when hitting the ball, and to be as efficient as possible.

In addition, the study showed that volunteers have a tendency to reach a better body stability to the ML than AP axis in unipodal standing. These data suggested therefore that the central nervous system can adopt different strategies for maintaining postural stability, depending mainly on the task demand and phases of the movement.

Based on the described study and analysis, we infer that the simplicity to fabricate the load cells and for mounting and calibrating the device, indicates the possibility of dissemination of this stabilometric apparatus, serving as a low-cost option for the academic and scientific community. However, this low-cost force platform was not designed to replace a complete synchronized monitoring system for different biomechanical dependent variables, such as center of mass, and electromyography signal, both important to the analysis of human postural behavior.

We believe that the developed platform can be used not only in sport analysis, but also for daily life tasks analysis, as a stabilometric device for measuring postural control and balance in different conditions. However, futures studies are required to validate this device and comparing its performance with that of others type of force platform, commercial and non-commercial.

\section{References}

Alvarenga R, Porto F, Braga R, Cantreva R, Espinosa G, Itaborahy A, Soares PP, Gurgel J. Construction and calibration of a low-cost force plate for human balance evaluation. Rev Port Cien Desp. 2011; 11(Suppl 2):961-4.

Bagesteiro LB, Laranja RAC, Tamagna A. The development of a force platform: Numerical and experimental analysis. Advances in Biochemical Engineering/Biotechnology. 1998; 39(2):325-30.
Barela AMF, Duarte M. Utilização da plataforma de força para aquisição de dados cinéticos durante a marcha humana. Journal of Motor Behavior. 2011; 6(1):56-61.

Cedraro A, Cappello A, Chiari L. A portable system for in-situ re-calibration of force platforms: Theoretical validation. Gait \& Posture. 2008; 28(3):488-94. PMid:18450453. http://dx.doi. org/10.1016/j.gaitpost.2008.03.006.

Dias JA, Mattos DJS, Wentz MD, Domenech SC, Kaufmann P, Borges NG Jr. Validity of a new stabilometric force platform for postural balance evaluation. Rev Bras Cineatropom Desempenho Hum. 2011; 13(5):367-72. http://dx.doi.org/10.5007/19800037.2011v13n5p367.

Duarte M, Freitas SMSF. Revision of posturography based on force plate for balance evaluation. Brazilian Journal of Physical Therapy. 2010; 14(3):183-92. PMid:20730361. http://dx.doi. org/10.1590/S1413-35552010000300003.

Geurts AC, Nienhuis B, Mulder TW. Intra subject variability of selected force-platform parameters in the quantification of postural control. Archives of Physical Medicine and Rehabilitation. 1993; 74(11):1144-50. PMid:8239951.

Gil-Gómez JA, Llorens R, Alcaniz M, Colomer C. Effectiveness of a Wii balance board-based system (eBaViR) for balance rehabilitation: a pilot randomized clinical trial in patients with acquired brain injury. Journal of Neuroengineering and Rehabilitation. 2011; 30(1):8-30. PMid:21600066. http:// dx.doi.org/10.1186/1743-0003-8-30.

Gurgel J, Porto F, Russomano T, Cambraia R, de Azevedo DFG, Glock FS, Beck JCP, Helegda S. Development and calibration of a pedal with force and moment sensors. In: Proceedings of the 28th International Conference of the Engineering in Medicine and Biology Society (IEEE 2006); 2006 Aug 30Sept 3; New York. New York: IEEE-EMBS; 2006. p. 4144-6. http://dx.doi.org/10.1109/IEMBS.2006.260719.

Gurgel JL, Porto F, Castro L, Russomano T, Beck J, Schroeder I. Desenvolvimento e avaliação de um procedimento de calibração para pedal sensor de forças e momentos. In: Anais do XI Congresso Brasileiro de Biomecânica; 2005 June 19-22; João Pessoa, PB, Brazil. João Pessoa: SBB; 2005. p. 1677-81. 
Herran AM, Zapirain BG, Zorrilla AM. Gait Analysis Methods: An overview of wearable and non-wearable systems, highlighting clinical applications. Sensors. 2014; 14(1):336294. PMid:24556672. http://dx.doi.org/10.3390/s140203362.

Huurnink A, Fransz DP, Kingma I, VanDieën JH. Comparison of a laboratory grade force platform with a Nintendo Wii Balance Board on measurement of postural control in singleleg stance balance tasks. Journal of Biomechanics. 2013; 46(7):1392-5. PMid:23528845. http://dx.doi.org/10.1016/j. jbiomech.2013.02.018.

Kavounoudias A, Gilhodes JC, Roll R, Roll JP. From balance regulation to body orientation: Two goals for muscle proprioceptive information processing? Experimental Brain Research. 1999; 124(1):80-8. PMid:9928792. http://dx.doi. org/10.1007/s002210050602.

Moreira D, Godoy JRP, Braz RG, Machado EFB, Santos HFS. Abordagem cinesiológica do chute no futsal e suas implicações clínicas. RBCM. 2004; 12(2):81-5.

Pagnacco G, Oggero E, Wright CHG. Biomedical instruments versus toys: a preliminary comparison of force platforms and the Nintendo Wii balance board. Biomedical Sciences Instrumentation. 2011; 47(2):12-7. PMid:21525589.

Rana N. Application of force sensing resistor (FSR) in design of pressure scanning system for plantar pressure measurement. In:
Proceedings of the 2nd International Conference on Computer and Electrical Engineering; 2009 Dec 28-30; Dubai. Dubai: UAE; 2009. p. 678-85. http://dx.doi.org/10.1109/ICCEE.2009.234.

Remaud A, Boyas S, Caron G, Bilodeau M. Attentional demands associated with postural control depend on task difficulty and visual condition. Journal of Motor Behavior. 2012; 44(5):329-40. PMid:22934664. http://dx.doi.org/10.1 080/00222895.2012.708680.

Roriz P, Carvalho C, Frazão O, Santos JL, Simões JA. From conventional sensors to fibre optic sensors for strain and force measurements in biomechanics applications: A review. Journal of Biomechanics. 2014; 47(6):1251-61. PMid:24612722. http:// dx.doi.org/10.1016/j.jbiomech.2014.01.054.

Rosa LM. Avaliação de equilíbrio dinâmico de jogadores de futebol durante o chute [thesis]. São Paulo: Universidade Estadual Paulista; 2010.

Urquiza MA. Desenvolvimento de uma plataforma de força multiaxial para instrumentação biomédica [dissertation]. Uberlândia: Universidade Federal de Uberlândia; 2005.

Vuillerme N, Nougier V, Prieur JM. Can vision compensate for a lower limbs muscular fatigue for controlling posture in humans? Neuroscience Letters. 2001; 308(2):103-6. PMid:11457570. http://dx.doi.org/10.1016/S0304-3940(01)01987-5. 